\title{
Protective effect of naringin against the LPS-induced apoptosis of PC12 cells: Implications for the treatment of neurodegenerative disorders
}

\author{
HUI WANG ${ }^{1}$, YOU SONG XU ${ }^{2}$, MIAO LIN WANG ${ }^{2}, \mathrm{CHAO} \mathrm{CHENG}^{2}$, RUI BIAN $^{2}$, \\ HAO YUAN ${ }^{2}$, YI WANG ${ }^{2}$, TING GUO ${ }^{2}$, LIN LIN ZHU ${ }^{2}$ and HANG ZHOU ${ }^{3}$ \\ ${ }^{1}$ Department of Neurosurgery, Traffic Hospital of Shandong Province, Jinan, Shandong 250031; ${ }^{2}$ Department of Neurosurgery, \\ The First Affiliated Hospital of Dalian Medical University, Dalian, Liaoning 116011; ${ }^{3}$ Department of Neurosurgery, \\ The 2nd Affiliated Hospital of Dalian Medical University, Dalian, Liaoning 116027, P.R. China
}

Received February 2, 2016; Accepted February 10, 2017

DOI: $10.3892 /$ ijmm.2017.2904

\begin{abstract}
Several studies have demonstrated that increased apoptosis plays an essential role in neurodegenerative disorders. It has been demonstrated that lipopolysaccharide (LPS) induces apoptosis largely through the production of intracellular reactive oxygen species (ROS) and inflammatory mediators. In this study, we investigated the potential protective mechanisms of naringin (Nar), a pummelo peel extract, on LPS-induced PC12 cell apoptosis. Nar pre-conditioning prior to stimulation with LPS for $18 \mathrm{~h}$ was a prerequisite for evaluating PC12 cell viability and the protective mechanisms of Nar. Nar significantly improved cell survival in a time- and concentration-dependent manner. On the one hand, Nar downregulated cytochrome P450 2E1 (CYP2E1),
\end{abstract}

Correspondence to: Dr Hang Zhou, Department of Neurosurgery, The 2nd Affiliated Hospital of Dalian Medical University, 467 Dalian Zhongshan Road, Dalian, Liaoning 116027, P.R. China

E-mail: 821234298@qq.com

Abbreviations: LPS, lipopolysaccharide; CYP, cytochrome P450 superfamily; CYP2E1, cytochrome P450 2E1; ROS, reactive oxygen species; Nrf2, nuclear factor erythroid 2-related factor 2; HO-1, heme oxygenase-1; SOD, superoxide dismutase; GSS, glutathione synthetase; IL-1, interleukin-1; TNF- $\alpha$, tumor necrosis factor- $\alpha$; HMGB1, high mobility group box 1 protein; COX-2, cyclooxygenase-2; TLR4, Toll-like receptor 4; MyD88, myeloid differentiation factor 88; TRAF6, TNF receptor-associated factor 6 ; NF- $\kappa B$, nuclear factor $\kappa-$ light-chain-enhancer of activated B cells; ERK, extracellular signalrelated protein kinase; JNK, c-Jun N-terminal kinase; MAPKs, mitogen activated protein kinases; AP-1, activator protein transcription factor-1; Fas, fatty acid synthase; FasL, Fas ligand; Bcl-2, B-cell lymphoma 2; Bcl-xL, B-cell lymphoma-extra large; Bax, Bcl-2associated $\mathrm{X}$ protein; Mito Cyto $\mathrm{c}$, mitochondrial cytochrome $c$; Cyto Cyto c, cytoplasmic cytochrome $c$; $\mathrm{LD}_{50}$, median lethal dose

Key words: naringin, neuroprotection, oxidative stress, inflammation, apoptosis inhibited the release of ROS, mitigated the stimulation of oxidative stress, and rectified the antioxidant protein contents of nuclear factor erythroid 2-related factor 2 (Nrf2), heme oxygenase-1 (HO-1), superoxide dismutase (SOD)2 and glutathione synthetase (GSS). On the other hand, Nar downregulated inflammatory gene and protein expression, including interleukin (IL)-1 $\beta$, IL-6, tumor necrosis factor (TNF)- $\alpha$, HMGB1, high mobility group box 1 protein (HMGB1), cyclooxygenase-2 (COX-2), the Toll-like receptor 4 (TLR4)-myeloid differentiation factor 88 (MyD88)-TNF receptor-associated factor 6 (TRAF6) pathway and downstream mitogen activated protein kinase (MAPK) phosphorylation, activator protein transcription factor-1 (AP-1) and nuclear factor (NF)- $\kappa$ B. Moroever, Nar markedly attenuated the cytochrome $c$ shift from the mitochondria to the cytosol and regulated caspase-3-related protein expression. To the best of our knowledge, this is the first study to report the antioxidant, anti-inflammatory and anti-apoptotic effects of Nar in neuronal-like PC12 cells. These results suggest that Nar can be utilized as a potential drug for the treatment of neurodegenerative disorders.

\section{Introduction}

With the progress made in the study of nervous system diseases, considerable evidence has been provided to support the hypothesis that oxidative stress, inflammation and apoptosis are closely associated with the development of neurodegenerative diseases (1-3). The use of the rat pheochromocytoma cell line, PC12, as an in vitro model system is quite acceptable for neurological and neurochemical studies $(4,5)$. Moreover, apoptosis can be induced by a variety of methods, including the use of lipopolysaccharide (LPS), a significant component of the Gram-negative bacteria cell wall, and it has been widely used in the study of neuronal apoptosis (6). The Toll-like receptor (TLR)4 can specifically bind with LPS and can thus trigger the release of inflammatory factors, free radicals and cysteinyl aspartate specific proteinases (known as caspases) that subsequently cause apoptosis (7-9). Hence, the development of a novel drug to reverse neurodegeneration through the inhibition of apoptosis is feasible. The exploration of new 
chemicals with high efficiency and low toxicity for the treatment of neurodegenerative diseases associated with oxidative stress, inflammation and apoptosis is of utmost importance.

Bioflavonoids, a group of polyphenolic substances, are found in most plants and are a sustainable supplement for human consumption (10). Due to their widespread availability, coupled with their low toxicity, they can be developed for use as therapeutic materials (11-14). Naringin (Nar; 4', 5,7-trihydroxyflavanone7-rhamnoglucoside) is a proverbial flavanone glycoside, which is found in abundance in citrus fruit, grapefruit and juices (15). Nar has been shown to have multiple biological and pharmacological properties, including anti-inflammatory, anti-carcinogenic, lipid-lowering and antioxidant activities (16-18).

In the study of pharmaceuticals for the treatment of central nervous system diseases, the critical threshold depends on whether or not these agents can cross the bloodbrain barrier (19). Naringenin (4',5,7-trihydroxyflavanone), a metabolic product of Nar, can easily cross the blood brain barrier (20), and due to this fact, the study of Nar instantly acquires more importance.

All in all, the mechanisms responsible for the protective effects of Nar against LPS-stimulated PC12 cell damage are not well understood. In the present study, we demonstrate that Nar protects PC12 cells from LPS-induced apoptosis by exerting antioxidant, anti-inflammatory and anti-apoptotic effects. Firstly, Nar reduces the level of intracellular reactive oxygen species (ROS) through the downregulation of cytochrome P450 2E1 (CYP2E1) expression directly, rather than through the upregulation of antioxidant-related protein expression, progressively maintaining the balance of the prooxidant and antioxidant enzyme system. Nar also attenuates the inflammatory response through the downregulation of the TLR4 pathway. Finally, we also explore the underlying antiapoptotic mechanisms in PC12 cells.

\section{Materials and methods}

Materials. PC12 rat pheochromocytoma cells were obtained from Shanghai Biochemistry Co., Ltd (Shanghai, China). 3-(4,5-Dimethylthiazol-2-yl)-2,5-diphenyltetrazolium bromide (MTT), RPMI-1640 medium, fetal bovine serum (FBS), penicillin and streptomycin, were obtained from Sigma Chemical Co. (St. Louis, MO, USA). 4-(2-Hydroxyethyl)-1piperazineethanesulfonic acid (HEPES), acridine orange (AO) and ethidium bromide (EB) fluorescent dyes, 4',6-damidino-2-phenylindole (DAPI) and TRIzol reagent were from Nanjing KeyGen Biotech Co. Ltd. (Nanjing, China). The reactive oxygen assay kit and DCFH-DA were provided by Dojindo Molecular Technologies, Inc. (Kumamoto, Japan). The Annexin V/propidium iodide (PI) apoptosis detection kit was obtained from Invitrogen Life Technologies, Inc. (Carlsbad, CA, USA).

Cell culture and treatment. The PC12 cells have been diffusely used as an analog neuron model in research (21). In this study, the cell culture medium contained RPMI-1640 with 5\% FBS, and appropriate penicillin and streptomycin. In the process of cell culture, the culture medium was changed 3 times a week.

MTT assay and cell viability. In order to determine the efficacy and dose, as well as optimal treaqtment time, the PC12 cells were treated with various concentrations $(0-2,000 \mathrm{ng} / \mathrm{ml})$ of Nar for $0.5,1$ and $2 \mathrm{~h}$ before being exposed to $400 \mu \mathrm{g} / \mathrm{ml}$ LPS for $18 \mathrm{~h}$ at $37^{\circ} \mathrm{C}$ with $5 \% \mathrm{CO}_{2}$. MTT solution was added to terminate the drug reaction process, and DMSO was then utilized to dissolve the crystals. The results were gauged by a POLARstar OPTIMA multi-detection microplate reader (Bio-Rad Laboratories, Inc., Hercules, CA, USA) at $490 \mathrm{~nm}$.

Morphological inspection. AO can penetrate viable cells, and is embedded in nuclear DNA to emit a bright green fluorescence. EB can only penetrate damaged cells, and is embedded in nuclear DNA to emit orange fluorescence. DAPI, as a fluorescent dye, can penetrate the cell membrane and nucleus of the double-stranded DNA. Thus, we used AO, EB, DAPI as dyes. The half lethal concentrations of LPS and the optimal protective concentrations of Nar were determined by MTT assays, and these were then used in subsequent experiments. The cells were treated with $\operatorname{Nar}(200,600$ and 1,000 $\mathrm{ng} / \mathrm{ml})$ for $1 \mathrm{~h}$ before being exposed to $400 \mu \mathrm{g} / \mathrm{ml} \mathrm{LPS}$ for $18 \mathrm{~h}$ at $37^{\circ} \mathrm{C}$ with $5 \% \mathrm{CO}_{2}$. The treated PC12 cells were inoculated into 6-well plates and stained with AO, EB and DAPI (the final concentration of $\mathrm{AO}$ and EB was $100 \mathrm{mg} / \mathrm{ml}$, and that of DAPI was $100 \mathrm{ng} / \mathrm{ml}$; these were dissolved in PBS). Staining was carried out at room temperature for 2-5 min, and the cells were then rinsed well with PBS. Finally, images of the cells were acquired utilizing an inverted fluorescence microscope (Olympus BX63; Olympus, Tokyo, Japan).

Transmission electron microscopy (TEM). The PC12 cells were subjected to various treatments as described above. The cells were collected in $1.5 \mathrm{ml}$ Eppendorf tubes, and $4 \%$ glutaraldehyde was then slowly added along the tube wall. The tubes were then placed in a refrigerator at $4^{\circ} \mathrm{C}$ for preservation. The the process of dehydration, infiltration, embedding, slicing and heavy metal staining was carried out in accordance with conventional TEM techniques. A transmission electron microscope was used to obtain microscopic images.

Determination of apoptosis. The PC12 cells were treated as described above. In this assay, we used the Annexin V/PI apoptosis detection kit (Invitrogen Life Technologies, Inc.) and a flow cytometer (FACSCalibur, Becton-Dickson, San Diego CA, USA). The cells ( $1 \times 10^{5} /$ sample) were washed twice with PBS, followed by centrifugation at $300 \times \mathrm{g}$ at $4^{\circ} \mathrm{C}$ for $5 \mathrm{~min}$. The cells were then resuspended in the $1 \mathrm{X}$ binding buffer $(100 \mu \mathrm{l})$, followed by the addition of Annexin V (5 $\mu \mathrm{l})$ and PI staining solution $(5 \mu \mathrm{l})$. Finally, the cells were exposed to room temperature for $10 \mathrm{~min}$, avoiding cell-cell contact, and $400 \mu \mathrm{l}$ $1 \mathrm{X}$ binding buffer was then added. Apoptosis was detected by flow cytometry. The third quadrant in the flow cytometric plots rerepsents the distribution of viable cells. The second and fourth quadrant are considered to indicate the distribution of apoptotic cells.

Intracellular ROS assay. The PC12 cells were treated as described above. The cells ( $1 \times 10^{5} /$ sample) were washed twice with PBS, followed by centrifugation at $300 \mathrm{x}$ a at $4^{\circ} \mathrm{C}$ for $5 \mathrm{~min}$. DCFH-DA solution was then added followed by incubation for $30 \mathrm{~min}$ in room temperature. The density distribution of ROS was analyzed by flow cytometry. 
Table I. The primer sequences used for RT-qPCR.

\begin{tabular}{|c|c|c|c|}
\hline Genes & $\begin{array}{c}\text { GenBank } \\
\text { accession no. }\end{array}$ & Forward primers $\left(5^{\prime} \rightarrow 3^{\prime}\right)$ & Reverse primers $\left(5^{\prime} \rightarrow 3^{\prime}\right)$ \\
\hline GAPDH & NM_017008.3 & GGCACAGTCAAGGCTGAGAATG & ATGGTGGTGAAGACGCCAGTA \\
\hline IL-1 $\beta$ & NM_031512.2 & CCCTGAACTCAACTGTGAAATAGCA & CCCAAGTCAAGGGCTTGGAA \\
\hline IL-6 & NM_012589.1 & ATTGTATGAACAGCGATGATGCAC & CCAGGTAGAAACGGAACTCCAGA \\
\hline TNF- $\alpha$ & NM_012675.3 & TCAGTTCCATGGCCCAGAC & GTTGTCTTTGAGATCCATGCCATT \\
\hline Fas & NM_139194.2 & CACAGCATTCAGTCCTATCCACAGA & CACAGCCAACCAGATGCTTCA \\
\hline FasL & NM_012908.1 & CACCAACCACAGCCTTAGAGTATCA & CACTCCAGAGATCAAAGCAGTTCC \\
\hline Bax & NM_017059.2 & CGAATTGGCGATGAACTGGA & CAAACATGTCAGCTGCCACAC \\
\hline
\end{tabular}

IL, interleukin; TNF, tumor necrosis factor; Fas, fatty acid synthase; FasL, Fas ligand; Bax, Bcl-2-associated X protein.

Detection of cytochrome c (Cyto c) release. The PC12 cells were subjected to various treatments as described above. The cells were washed with PBS, fixed with $4 \%$ paraformaldehyde for $15 \mathrm{~min}$ at $4^{\circ} \mathrm{C}$, washed with PBS again, and then permeabilized with $0.2 \%$ Trixon- 100 for $8 \mathrm{~min}$. Non-specific binding was blocked by incubating the cells in $3 \% \mathrm{BSA}$ for $45 \mathrm{~min}$ at $37^{\circ} \mathrm{C}$, and the cells were then incubated with the primary antibody overnight at $4^{\circ} \mathrm{C}$. The cells were then washed twice with PBS. The cells were incubated with the secondary antibody for $1 \mathrm{~h}$ at $37^{\circ} \mathrm{C}$, washed with PBS, and then stained with DAPI $(1 \mu \mathrm{g} / \mathrm{ml})$ for 5 min. A laser scanning confocal microscope (TCS SP5, Leica Microsystems CMS GmbH., Mannheim, Germany) was used to acquire images. Cyto $c$ was combined with the antibody to emit green light, and DAPI was used to stain the nuclei blue. In addition, we respectively extracted the cytoplasmic and mitochondrial proteins for use in western blot analysis.

Reverse transcrtiption-quantitative PCR (RT-qPCR). Total RNA was extracted from the cells using TRIzol reagent. One microgram total RNA from each sample was then converted into complementary DNA (cDNA) by reverse transcription [using the PrimeScript ${ }^{\mathrm{TM}}$ RT reagent kit (Takara, Dalian, China)]. Quantitative PCR (qPCR) was performed to gauge the mRNA levels using the 7500 Real-Time PCR system (Applied Biosystems, Foster City, CA, USA). The PCR cycling conditions were as follows: $94^{\circ} \mathrm{C}$ pre-degeneration for $4 \mathrm{~min}, 94^{\circ} \mathrm{C}$ degeneration for $30 \mathrm{sec}, 60^{\circ} \mathrm{C}$ annealing for $30 \mathrm{sec}, 72^{\circ} \mathrm{C}$ extension for $2 \mathrm{~min}$, for 35 cycles. The data were analyzed using System SDS software (Applied Biosystems). The expression level of the GAPDH gene was considered as a standard. The relative gene expression levels of interleukin (IL)-1 $\beta$, IL-6, tumor necrosis factor- $\alpha$ (TNF$\alpha$ ), fatty acid synthase (Fas), Fas ligand (FasL) and Bcl-2-associated $\mathrm{X}$ protein (Bax) were expressed as a percentage of the expression of GAPDH. Respective primers (Table I) were applied by calculating target gene expression.

Western blot analysis. We used lysis buffer to extract the total proteins, and the extracted proteins were then quantified using the Bradford assay kit (Blossom Bio Inc., Hangzhou, China). The cells were lysed using lysis buffer containing phenylmethanesulfonyl fluoride (PMSF) on ice for $30 \mathrm{~min}$, The lysates were then centrifuged at $20,000 \mathrm{x} \mathrm{g}$ at $4^{\circ} \mathrm{C}$ for $5 \mathrm{~min}$. The supernatant was placed in $-20^{\circ} \mathrm{C}$. A total of $50 \mu \mathrm{g}$ protein was placed on a $12 \%$ SDS-PAGE gel and separated electrophoretically. The target proteins were then transferred onto PVDF membranes (Millipore, Billerica, MA, USA). After blocking the PVDF membranes in 5\% dried skim milk (Boster Biological Technology, Wuhan, China) for $3 \mathrm{~h}$ at room temperature, the membranes were incubated overnight at $4{ }^{\circ} \mathrm{C}$ with primary antibodies (Table II). Subsequently, the membranes were incubated at room temperature for $2 \mathrm{~h}$ with horseradish peroxidase-conjugated goat anti-rabbit IgG or goat anti-mouse IgG antibodies at a 1: 2,000 dilution (Beyotime Institute of Biotechnology, Beijing, China). Protein detection was performed by enhanced chemiluminescence (ECL) and imaging was carried out using a BioSpectrum Gel Imaging System (HR410, UVP, USA). In order to eliminate the variations, the expression level of the GAPDH gene was considered as a standard. It should be noted that all protein extractions were carried out once, and thus the internal reference was same in this experiment. Moreover, in order to detect the intra- and extranuclear content of Cyto $c$, we used the Nuclear and Cytoplasmic Protein Extraction kit (Blossom Bio Inc.) to extract the protein, and the remaining process was carried out as described above..

Statistical analysis. All data are presented as the means \pm standard deviation (SD). The data between groups were compared by one-way analysis of variance (ANOVA) and inter-group differences were compared using a t-test. A value of $\mathrm{p}<0.05$ was considered to indicate a statistically significant difference.

\section{Results}

Effects of Nar on LPS-induced cell death. The chemical structures of Nar is shown in Fig. 1A. MTT assay is widely used in pharmacodynamics experiments $(22,23)$. Treatment with various concentrations $(200,600$ and $1,000 \mathrm{ng} / \mathrm{ml})$ of Nar for $1 \mathrm{~h}$ prior to treatment with LPS $(400 \mu \mathrm{g} / \mathrm{ml}, 18 \mathrm{~h})$ induced a time and dosedependent increase in the cell survival rate (cell viability increased to $61.2 \pm 1.3,73.1 \pm 1.4$ and $87.36 \pm 1.8 \%$, respectively) (Fig. 1B).

Treatment with Nar at the range of $0-2,000 \mathrm{ng} / \mathrm{ml}$ had no obvious effect on the survival rate of the PC12 cells (Fig. 1C). Therefore, the Nar concentrations of 200, 600 and 1,000 ng/ $\mathrm{ml}$ used in the subsequent experiments were not considered to be toxic to the cells. In addition, the viability of the PC12 cells exposed to LPS ( $400 \mu \mathrm{g} / \mathrm{ml}, 18 \mathrm{~h})$ was decreased to 
Table II. Information for the antibodies used in the present study.

\begin{tabular}{|c|c|c|c|}
\hline Antibodies & Sources & Dilutions & Companies \\
\hline GAPDH & Rat & $1: 5,000$ & Proteintech Group, Inc., Chicago, IL, USA \\
\hline Nrf2 & Rabbit & $1: 1,000$ & Proteintech Group, Inc., Chicago, IL, USA \\
\hline $\mathrm{HO}-1$ & Rabbit & $1: 1,000$ & Proteintech Group, Inc., Chicago, IL, USA \\
\hline SOD2 & Rabbit & $1: 1,000$ & Proteintech Group, Inc., Chicago, IL, USA \\
\hline GSS & Rabbit & $1: 1,000$ & Proteintech Group, Inc., Chicago, IL, USA \\
\hline CYP2E1 & Rabbit & $1: 1,000$ & Proteintech Group, Inc., Chicago, IL, USA \\
\hline HMGB1 & Rabbit & $1: 1,000$ & Proteintech Group, Inc., Chicago, IL, USA \\
\hline $\mathrm{COX}-2$ & Rabbit & $1: 1,000$ & Proteintech Group, Inc., Chicago, IL, USA \\
\hline TLR4 & Rabbit & $1: 1,000$ & Proteintech Group, Inc., Chicago, IL, USA \\
\hline MyD88 & Rabbit & $1: 1,000$ & Proteintech Group, Inc., Chicago, IL, USA \\
\hline TRAF6 & Rabbit & $1: 1,000$ & Proteintech Group, Inc., Chicago, IL, USA \\
\hline $\mathrm{NF}-\kappa \mathrm{B}$ & Rabbit & $1: 1,000$ & Proteintech Group, Inc., Chicago, IL, USA \\
\hline AP-1 & Rabbit & $1: 1,000$ & Proteintech Group, Inc., Chicago, IL, USA \\
\hline Bak & Rabbit & $1: 1,000$ & Proteintech Group, Inc., Chicago, IL, USA \\
\hline Bcl-2 & Rabbit & $1: 1,000$ & Proteintech Group, Inc., Chicago, IL, USA \\
\hline Bcl-xL & Rabbit & $1: 1,000$ & Proteintech Group, Inc., Chicago, IL, USA \\
\hline Caspase-9 & Rabbit & $1: 1,000$ & Proteintech Group, Inc., Chicago, IL, USA \\
\hline Cyto $c$ & Rabbit & $1: 1,000$ & Proteintech Group, Inc., Chicago, IL, USA \\
\hline Caspase- 8 & Rabbit & $1: 1,000$ & Proteintech Group, Inc., Chicago, IL, USA \\
\hline Caspase-3 & Rabbit & $1: 1,000$ & Proteintech Group, Inc., Chicago, IL, USA \\
\hline p53 & Rabbit & $1: 1,000$ & Proteintech Group, Inc., Chicago, IL, USA \\
\hline p-p38 & Rabbit & $1: 1,000$ & Bioworld Technology, Inc., St. Louis Park, MN, USA \\
\hline p-38 & Rabbit & $1: 1,000$ & Bioworld Technology, Inc., St. Louis Park, MN, USA \\
\hline p-ERK & Rabbit & $1: 1,000$ & Bioworld Technology, Inc., St. Louis Park, MN, USA \\
\hline ERK & Rabbit & $1: 1,000$ & Bioworld Technology, Inc., St. Louis Park, MN, USA \\
\hline p-JNK & Rabbit & $1: 1,000$ & Bioworld Technology, Inc., St. Louis Park, MN, USA \\
\hline JNK & Rabbit & $1: 1,000$ & Bioworld Technology, Inc., St. Louis Park, MN, USA \\
\hline
\end{tabular}

Nrf2, nuclear factor erythroid 2-related factor 2; HO-1, heme oxygenase-1; SOD2, superoxide dismutase 2; GSS, glutathione synthetase; CYP2E1, cytochrome P450 2E1; HMGB1, high mobility group box 1 protein; COX-2, cyclooxygenase-2; TLR4, toll-like receptor 4; My88, myeloid differentiation factor 88; TRAF6, TNF receptor-associated factor 6; NF- $\kappa \mathrm{B}$, nuclear factor- $\kappa$-light-chain-enhancer of activated B cells; AP-1, activator protein transcription factor-1; Bcl-2, B-cell lymphoma 2; Bcl-xL, anti-apoptotic Bcl-2 family protein; caspase, cysteinyl aspartate specific proteinase; cytochrome $c$, Cyto $c$; ERK, extracellular signal-related protein kinase; JNK, c-Jun N-terminal kinase.

$50.15 \pm 1.1 \%$ (Fig. 1D); thus, LPS at the concentration of $400 \mu \mathrm{g} /$ $\mathrm{ml}$ was selected for use in the subsequent experiments to induce cell damage. Our results demonstrated the potential protective effects of Nar on LPS-induced PC12 cell viabiltiy in a time- and dose-dependent manner.

Cell morphology. Black and white microscopic images and images of $\mathrm{AO} / \mathrm{EB}$ and DAPI staining provided morphological evidence to confirm our results. As shown in Fig. 2A, the control PC12 cells exhibited green fluorescence, whereas the model group cells exposed to LPS exhibited yellowstained cells, indicating apoptosis. The apoptotic cells were significantly decreased by pre-treatment with Nar (1,000 ng/ $\mathrm{ml}, 1 \mathrm{~h}$ ), as evidenced by the decreased number of yellowstained cells.

In order to further confirm our results, the changes in the ultrastructure of the $\mathrm{PC} 12$ cells were observed under a transmission electron microscope. As shown in Fig. 2B, the control group cells exhibited intact cell membranes, intact nuclei, and a large number of villi structures; however, the cells exposed to LPS exhibited distinct changes, including cytoplasmic vacuoles, as well as the disappearance of microvilli structures. Compared with the model group exposed to LPS, pre-treatment with Nar markedly reversed the above-mentioned changes.

Finally, flow cytometry was used to measure the amount of apoptotic cells (Fig. 2C). In relation to the condition, LPS provoked a 14-fold increase in the number of apoptotic cells (from $3.9 \%$ of cells in the control condition to $55 \%$ of cells following exposure to LPS). However, pre-treatment with Nar decreased the apoptotic rate significantly (Fig. 2C).

Effects of Nar on intracellular ROS levels. Exposure to LPS prompted the release of a large number of ROS from the cells (Fig. 3); however, ROS production was markedly inhibited by pre-treatment with Nar, particularly pre-treatment Nar at $1,000 \mathrm{ng} / \mathrm{ml}$. Our findings demonstrated that the LPS-induced PC12 cell apoptosis may be associated with oxidative stress, as also previously demonstrated $(4,24)$. However, Nar protected the $\mathrm{PC} 12$ cells from apoptosis and attenuated the production of intracellular ROS. 
A<smiles>C[C@@H]1O[C@H](O[C@H]2C(Oc3cc(O)c4c(c3)OC(c3ccc(O)cc3)CC4=O)OC(CO)[C@@H](O)[C@H]2O)[C@H](O)[C@@H](O)[C@H](O)[C@@H]1O</smiles>

C

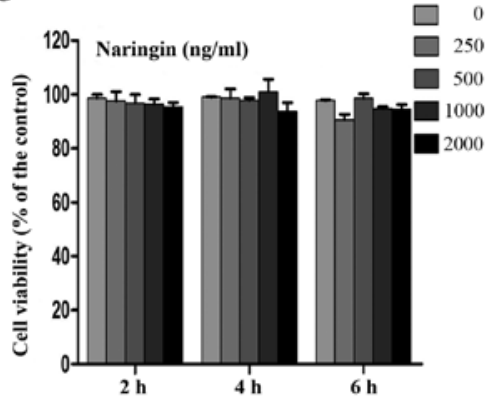

B
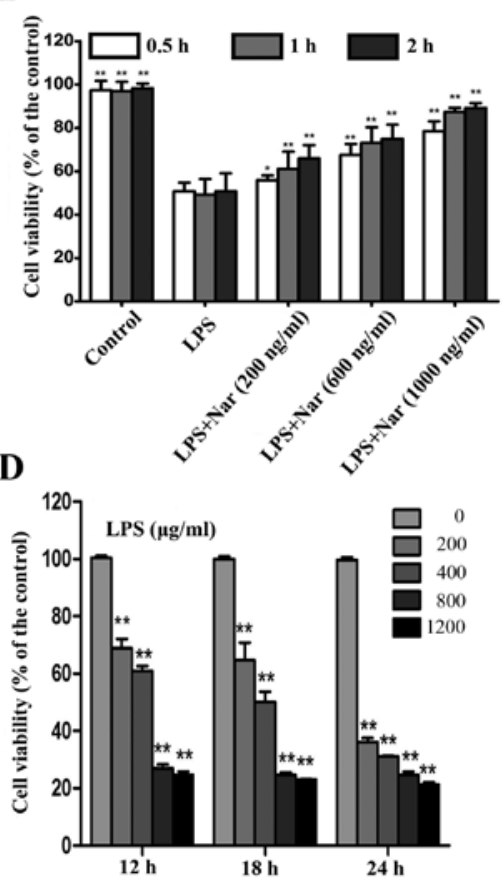

Figure 1. (A) Chemical structure of naringin (Nar). (B) Pre-treatment with Nar at various concentrations (200,600 and 1,000 ng/ml) and for different periods of time $(0.5,1$ and $2 \mathrm{~h}$ ) mitigated lipopolysaccharide (LPS)-induced cell death. (C) Safe dose of Nar to maintain cell viability. (D) Dose- and time-dependent effects of LPS on cell viability. Data are presented as the means $\pm \mathrm{SD}$ ( $\mathrm{n}=5$ treatment groups). ${ }^{\mathrm{p}}<0.05$ and ${ }^{* *} \mathrm{p}<0.01$ compared with the LPS group.

A
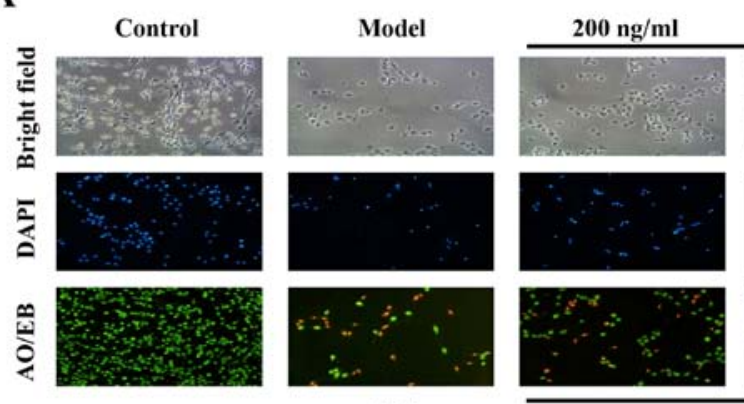

$600 \mathrm{ng} / \mathrm{ml}$
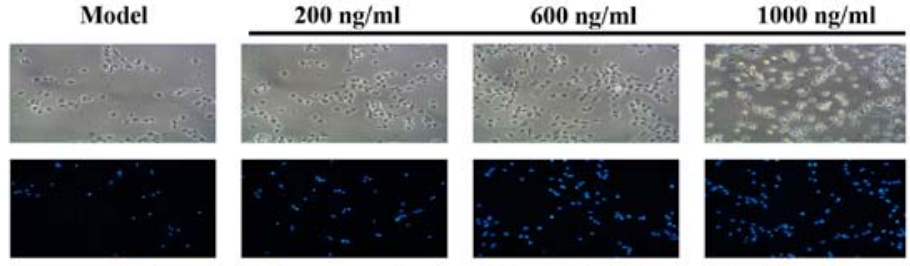

B
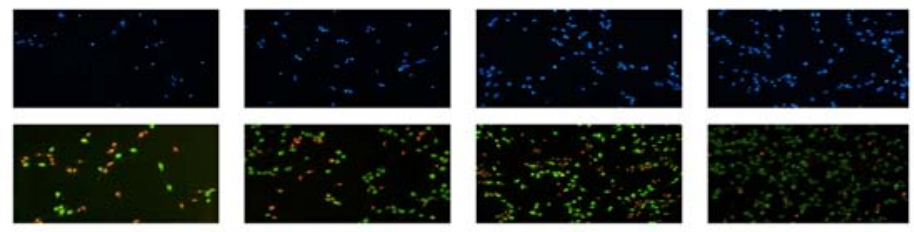

LPS

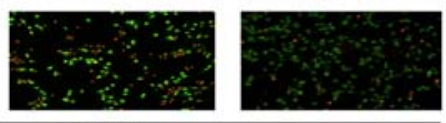

LPS+Nar
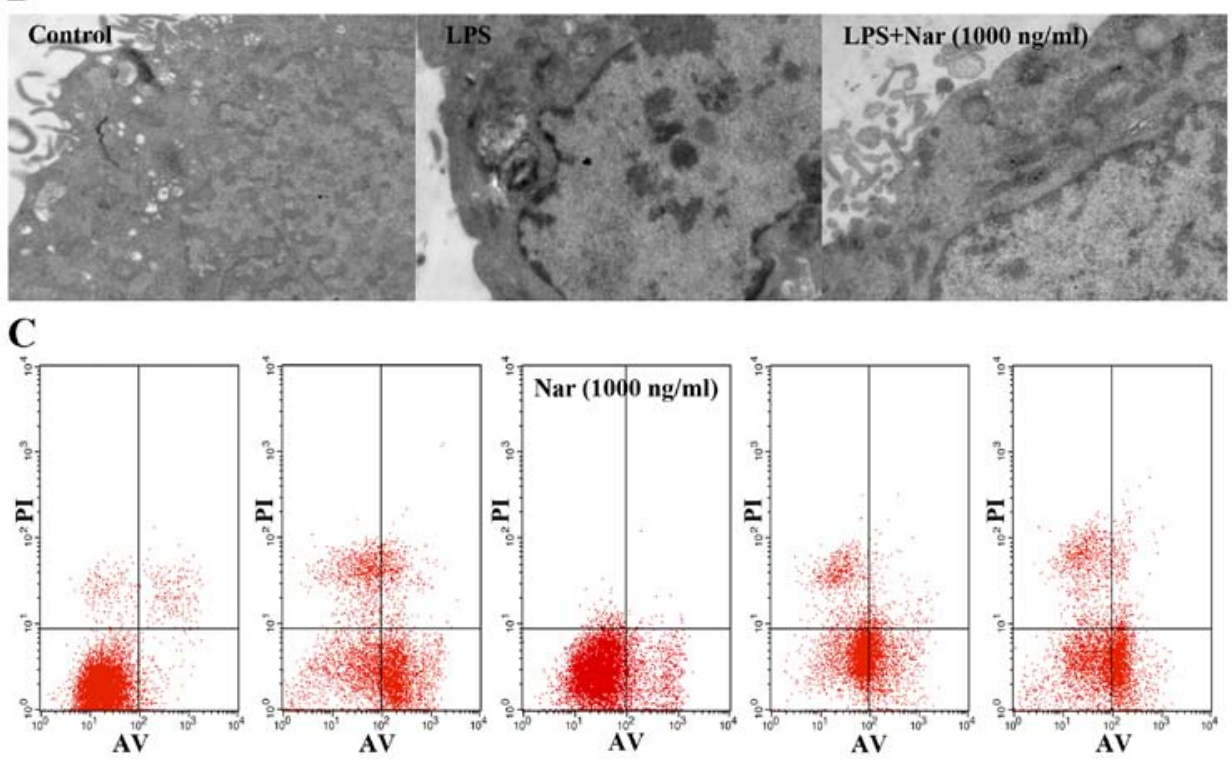

Figure 2. (A) Morphological and fluorescence images of PC12 cells stained with acridine orange and ethidium bromide AO/EB and DAPI (x100 magnification). (B) Protective effect of the naringin (Nar) on the ultra-structure of PC12 cells (x40,000 magnification). (C) Detection of apoptosis by flow cytometry. Data are presented as the means $\pm \mathrm{SD}\left(\mathrm{n}=5\right.$ treatment groups). ${ }^{*} \mathrm{p}<0.05$ and ${ }^{* *} \mathrm{p}<0.01$ compared with model group. 

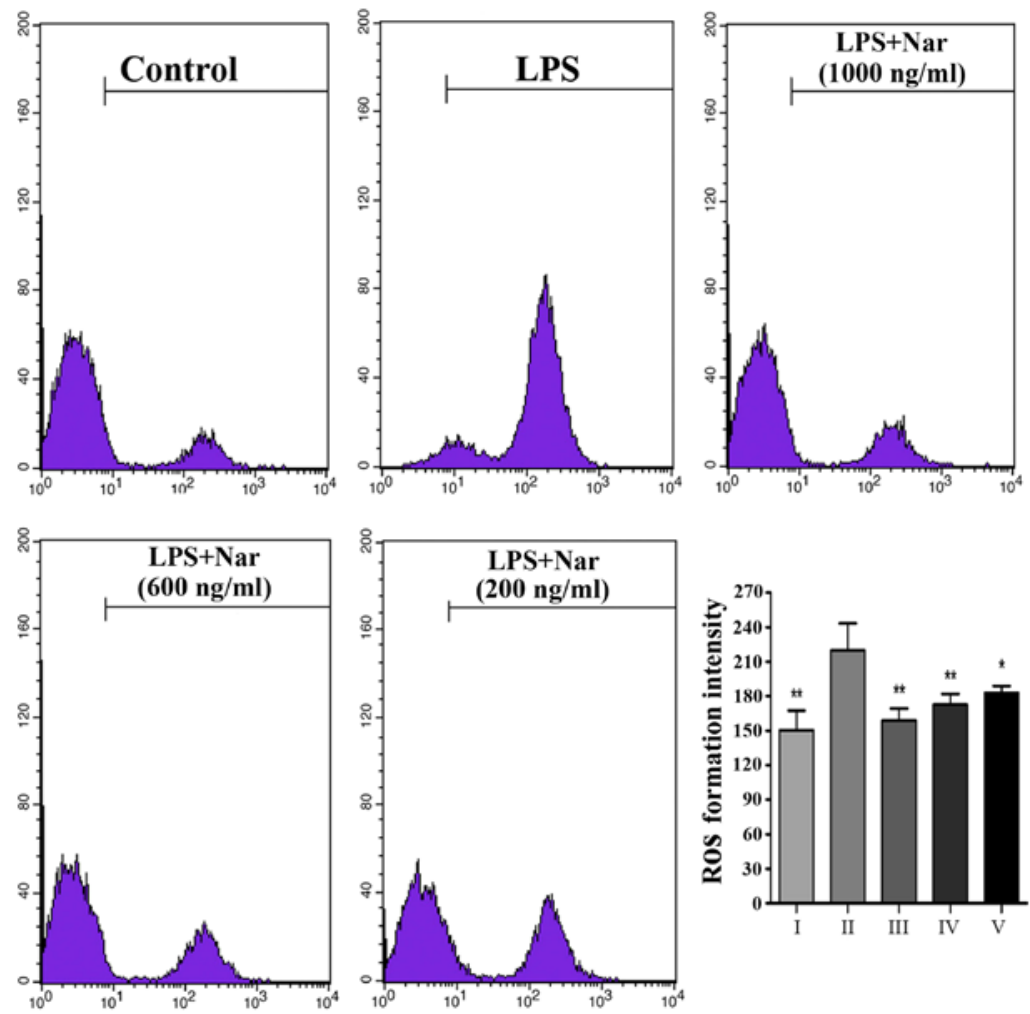

Figure 3. Level of intracellular reactive oxygen species (ROS) detected by flow cytometry and the intracellular ROS formation intensity. Data are presented as the means $\pm \mathrm{SD}$ ( $\mathrm{n}=5$ treatment groups). ${ }^{*} \mathrm{p}<0.05$ and ${ }^{* *} \mathrm{p}<0.01$ compared with the LPS group. For the bar chart: I, control; II, LPS only; III, Nar at 1,000 ng/ml; $\mathrm{IV}, \mathrm{Nar}$ at $600 \mathrm{ng} / \mathrm{ml}$; and $\mathrm{V}, \mathrm{Nar}$ at $200 \mathrm{ng} / \mathrm{ml}$.
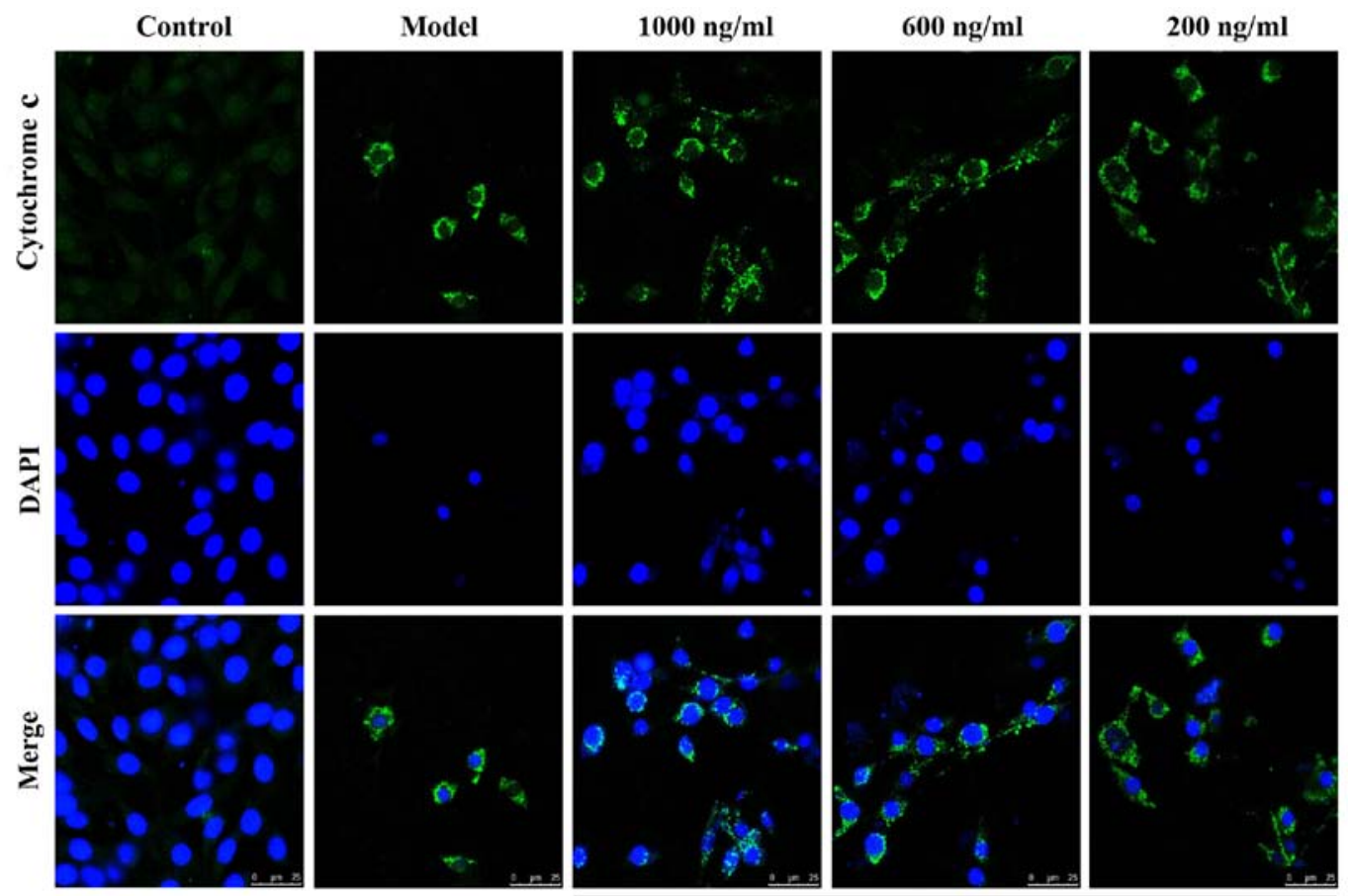

LPS

LPS+Naringin

Figure 4. Immunofluorescence of cytochrome $c$ (Cyto $c$ ) (x800 magnification). Green fluorescence reflects staining with cytochrome $c$ fluorescent antibody, and blue fluorescence reflects staining with DAPI, which directly reflects nuclear staining. Compared with the LPS group, with the increasing concentration of naringin, the cell nuclei returned to their normal form, the number of viable cells increased, and staining for extracellular cytochrome $c$ decreased.

Suppression of Cyto c release. As is known, Cyto $c$ plays a vital role in the process of apoptosis $(25,26)$. In Fig. 4 , green fluorescence reflects staining with Cyto $c$ fluorescent antibody, and blue fluorescence reflects staining with DAPI, which 

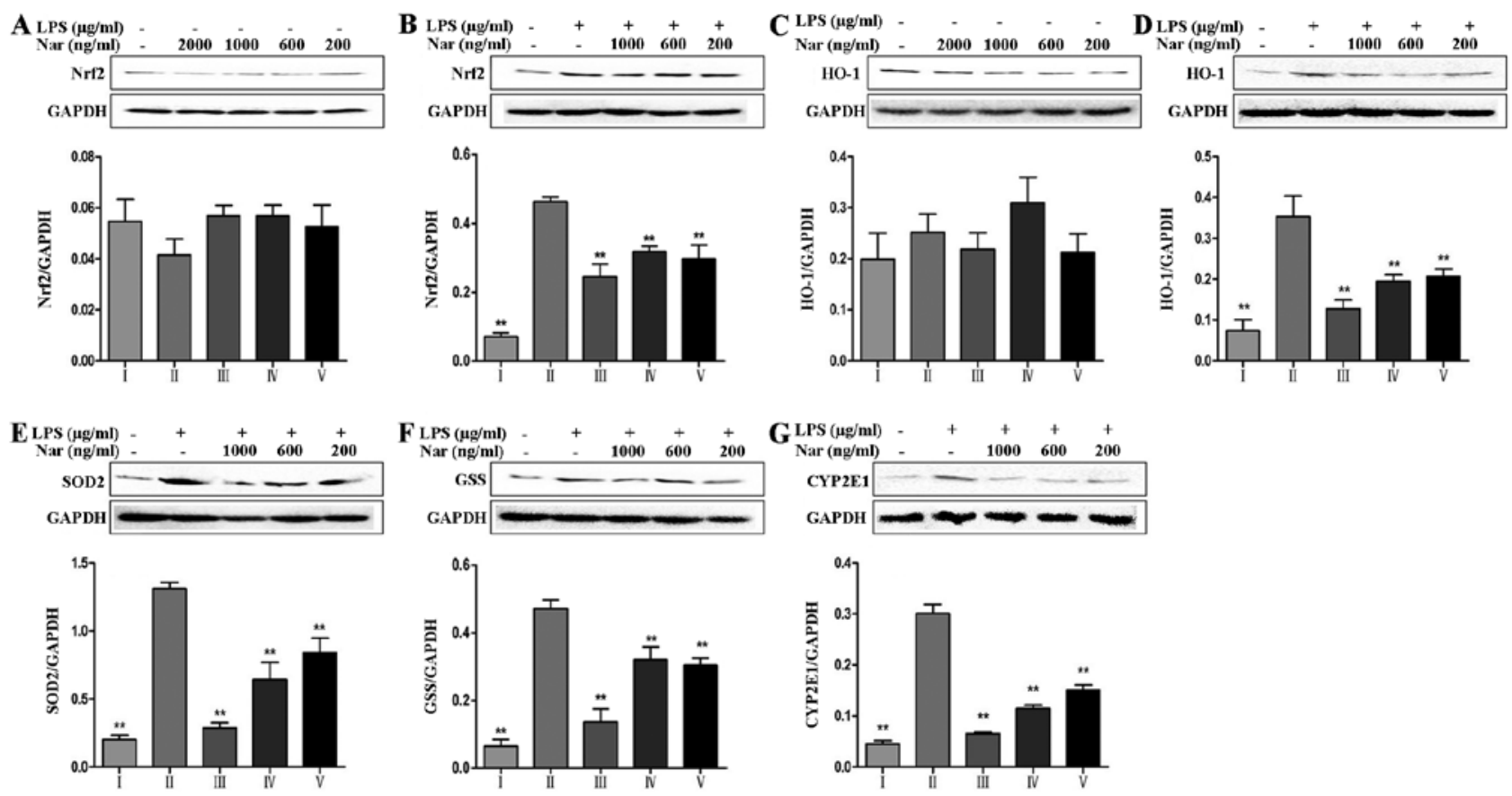

Figure 5. Effects of naringin (Nar) on the levels of oxidative stress-related proteins. (A and B) Nuclear factor E2-related factor 2 (Nrf2), (C and D) heme oxygenase-1 (HO-1), (E) superoxide dismutase 2 (SOD2), (F) glutathione synthetase (GSS) and (G) cytochrome P450 2E1 (CYP2E1). Values are expressed as the means \pm SD ( $n=5$ treatment groups). ${ }^{*} \mathrm{p}<0.05$ and ${ }^{* *} \mathrm{p}<0.01$ compared with the LPS group. For the bar charts: I, control; II, LPS only; III, Nar at 1,000 ng/ml; IV, Nar at $600 \mathrm{ng} / \mathrm{ml}$; and V, Nar at $200 \mathrm{ng} / \mathrm{ml}$.

directly reflects nuclear staining. As shown in the merge image of Fig. 4, little fluorescence was observed in the control group, whereas in the LPS group, even though the number of viable cells was significantly decreased, the cell size was reduced and the nuclear staining also decreased, the content of extranuclear Cyto $c$ was still evident. Thus, there was a mass of diffuse cytoplasmic fluorescence. As also shown in Fig. 8G and H, Nar effectively abated the transfer of Cyto $c$ from the mitochondria to the cytoplasm. Therefore, it exerted an anti-apoptotic effect.

Effects of the Nar on the expression levels of oxidative stressrelated markers. It is worth noting that nuclear factor E2-related factor 2 (Nrf2) can mediate antioxidant gene expression (27). As shown in Fig. 5A and B, in the absence of LPS, treatment of the PC12 cells with Nar at any concentration did not alter the total Nrf2 protein level compared with the untreated control group. However, in the cells exposed to LPS, the total Nrf2 protein level was significantly increased, indicating the resistance to the oxidative stress reaction through compensatory mechanisms. Pre-treatment of the cells with Nar improved the cell survival rate and gradually corrected the balance of the intracellular total Nrf2 levels. In addition, other oxidative-related proteins, including heme oxygenase-1 (HO-1), superoxide dismutase 2 (SOD2) and glutathione synthetase (GSS) also exhibited the same trend in expression (Fig. 5C-F).

It is worth emphasizing that CYP2E1 plays an essential role in the production of ROS (28). As shown in Fig. 5G, relative to the specific condition, LPS provoked a 6.7-fold increase in the CYP2E1 levels (from $4.5 \%$ of cells in the control condition to $30.1 \%$ of cells exposed to LPS). However, pre-treatment with Nar significantly decreased the levels of CYP2E1.
Effects of the Nar on the expression levels of inflammatory cytokines and TLR4-related proteins. As shown in Fig. 6, we detected the expression levels of inflammation-related genes and proteins, including IL-1 $\beta$, IL- 6 , TNF- $\alpha$, high mobility group box 1 protein (HMGB1) and cyclooxygenase-2 (COX-2), as well as TLR4-related proteins, including TLR4, myeloid differentiation factor 88 (MyD88), TNF receptor-associated factor 6 (TRAF6), nuclear factor $\kappa$-light-chain-enhancer of activated $B$ cells $(\mathrm{NF}-\kappa \mathrm{B})$ and activator protein transcription factor-1 (AP-1), and the results revealed that LPS promoted the overexpression of inflammation-related proteins, whereas pre-treatment with Nar decreased the levels of inflammationrelated proteins in a dose-dependent manner.

Effects of Nar on the expression levels of mitogen-activated protein kinase (MAPK) phosphorylation. Consistent with the in vitro experimental results of the TLR4 pathway (Fig. 6F-J), we detected the levels of MAPK phosphorylation at the same time. LPS markedly increased the protein expression levels (p-ERK, p-JNK, p-p38) by 4.6-, 3.6- and 14.3-fold. However, Nar markedly decreased MAPK phosphorylation (Fig. 7). On the whole, pre-treatment with Nar significantly inhibited the LPS-induced activation of extracellular signal-related protein kinase (ERK), c-Jun N-terminal kinase (JNK) and the p38 signaling pathways. Furthermore, our results demonstrated that the anti-inflammatory effects of Nar are associated with the inhibition of the TLR4 pathway.

Effects of Nar on the expression levels of apoptosis-related genes and proteins. As shown in Fig. 8, LPS increased the expression levels of Fas, FasL and Bax (Fig. 8A-C). Furthermore, 


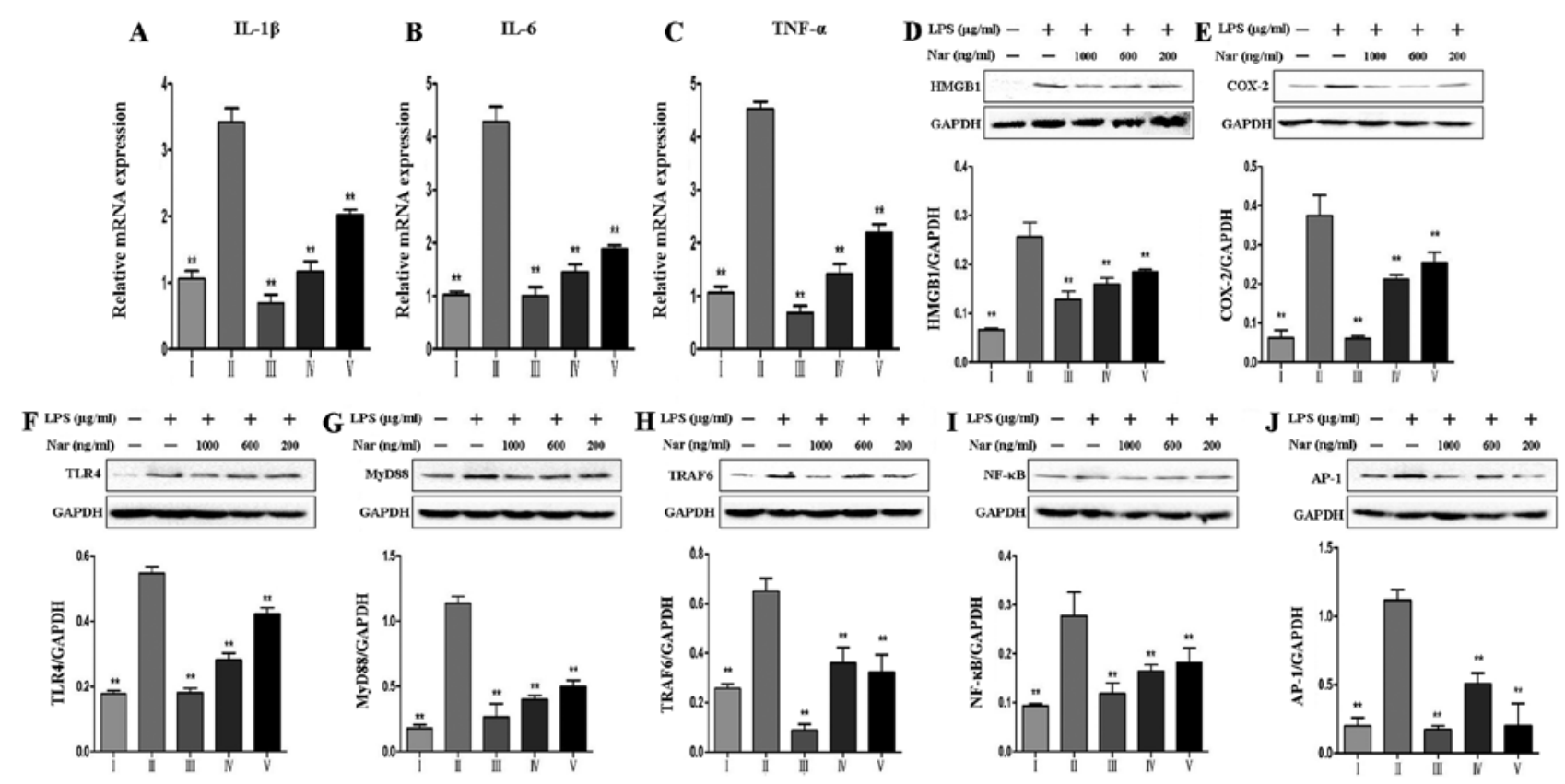

Figure 6. Effects of naringin (Nar) on the expression of inflammation-related markers. mRNA levels of (A) interleukin (IL)-1 $\beta$, (B) IL-6, (C) tumor necrosis factor- $\alpha$ (TNF- $\alpha$ ), and protein expressions of (D) high mobility group box 1 protein (HMGB1), (E) cyclooxygenase-2 (COX-2), (F) Toll-like receptor 4 (TLR4), (G) myeloid differentiation factor 88 (MyD88), (H) TNF receptor-associated factor 6 (TRAF6), (I) nuclear factor $\kappa$-light-chain-enhancer of activated B cells (NF- $\mathrm{kB}$ ) and (J) activator protein transcription factor-1 (AP-1). Values are expressed as the means $\pm \mathrm{SD}$ ( $\mathrm{n}=5$ treatment groups). ${ }^{* *} \mathrm{p}<0.01 \mathrm{compared}$ with the LPS group. For the bar charts: I, control; II, LPS only; III, Nar at 1,000 ng/ml; IV, Nar at $600 \mathrm{ng} / \mathrm{ml}$; and V, Nar at $200 \mathrm{ng} / \mathrm{ml}$.

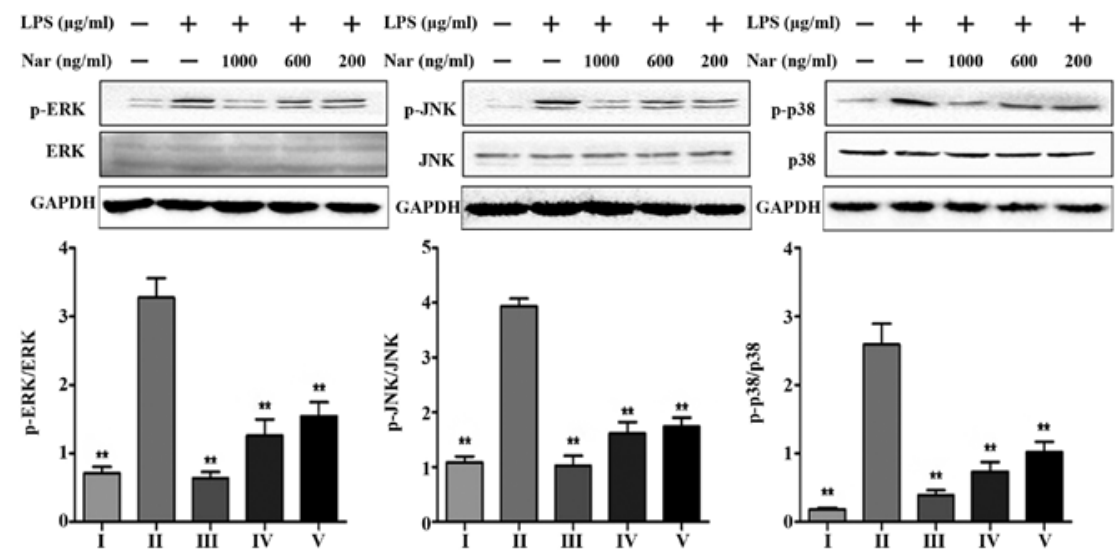

Figure 7. Effects of naringin (Nar) on the phosphorylation levels of mitogen activated protein kinases (MAPKs). Values are expressed as the means \pm SD ( $\mathrm{n}=5$ treatment groups). ${ }^{* *} \mathrm{p}<0.01$ compared with the LPS group. For the bar charts: I, control; II, LPS only; III, Nar at 1,000 ng/ml; IV, Nar at $600 \mathrm{ng} / \mathrm{ml} ;$ and V, Nar at $200 \mathrm{ng} / \mathrm{ml}$.

LPS increased the protein levels of Bak, caspase-9, caspase-8, caspase-3 and 53 , and decreased the levels of the anti-apoptotic proteins, Bcl-xL, B-cell lymphoma 2 (Bcl-2). However, pre-treatment with Nar markedly decreased the levels of Fas, FasL, Bax, Bak, caspase-9, caspase-3 and p53. The levels of $\mathrm{Bcl}-2$ and $\mathrm{Bcl}-\mathrm{xL}$ were evidently upregulated by 1.9 -fold (from 21.9 to $42.5 \%)$ and 3.0 -fold (from 10.5 to $31.7 \%)(\mathrm{p}<0.01)$ by pre-treatment with $\mathrm{Nar}(1,000 \mathrm{ng} / \mathrm{ml})$.

\section{Discussion}

Nar, a flavanone glycoside of plants and fruits, has been shown to possess potent antioxidant (29), anti-inflammatory proper- ties (30-32). As it has been previously reported, the long-term consumption of Nar improves memory in animal models of neurodegenerative diseases (33-35). To date, to the best of our knowedge, in vitro research on the effects of Nar on neurons is limited. Thus, in this study, in order to explore and confirm the potential neuroprotective effects of Nar, we examined the effects of Nar on the LPS-induced apoptosis of PC12 cells in vitro. In addition, we investigated the potential underlying mechanisms.

On the one hand, chronic toxicological assessment analysis of Nar has indicated that Nar is a substance with low toxicity (36), and our results also demonstrated this fact. On the other hand, naringenin, a metabolic product of Nar, can easily 

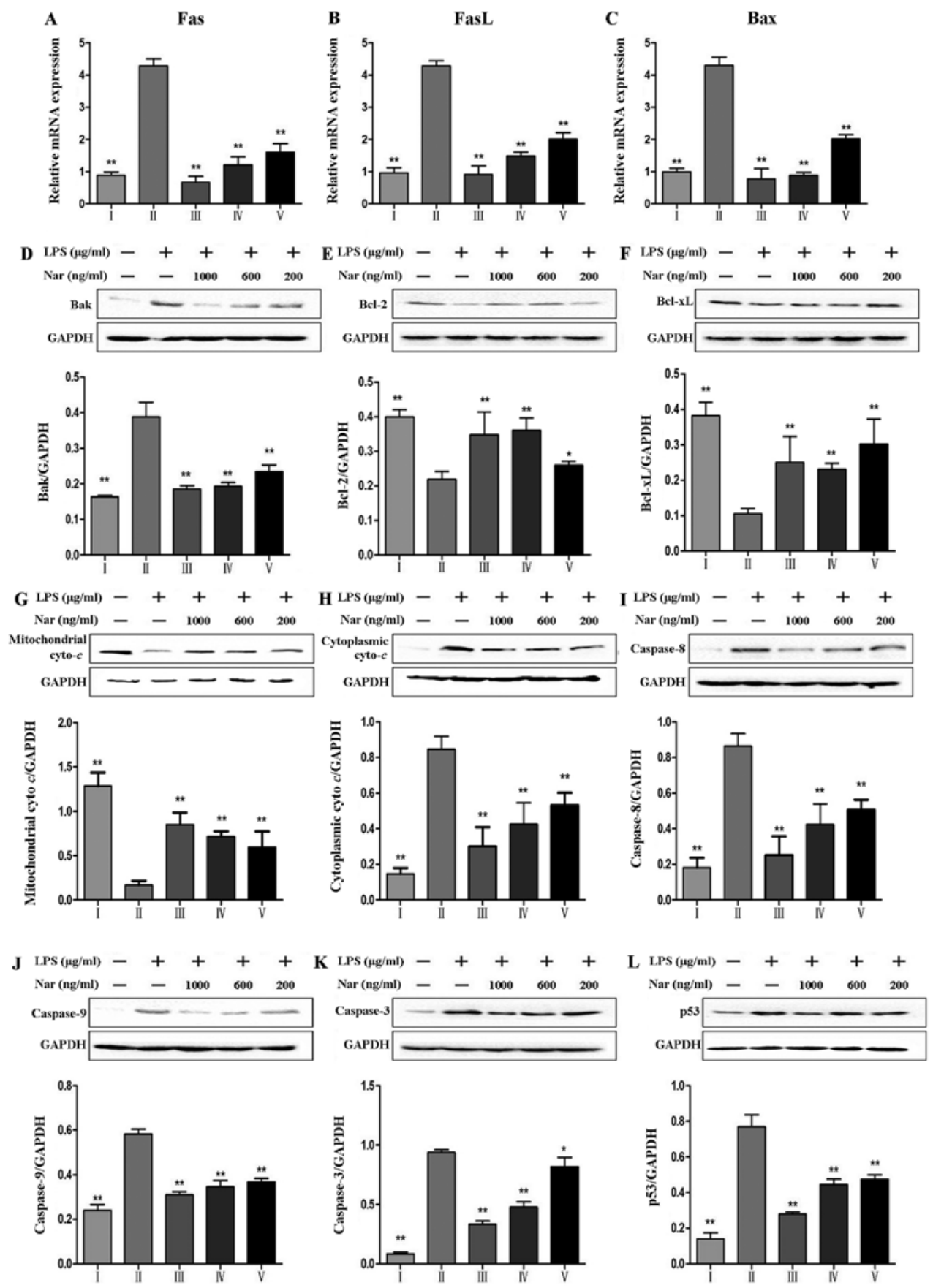

Figure 8. Effects of naringin (Nar) on the expression of apoptosis-related genes and proteins. mRNA expression of (A) fatty acid synthase (Fas), (B) Fas ligand (FasL), (C) Bcl-2-associated X protein (Bax), and (D) protein expression of Bak, (E) Bcl-2, B-cell lymphoma 2 (Bcl-2), (F) Bcl-xL, (G) mitochondrial cytochrome $c$ (Mito Cyto $c$ ) (H) cytoplasmic cytochrome $c$ (Cyto Cyto $c$ ), (I) caspase-8, (J) capase-9, (K) caspase-3 and (L) p53. "p $<0.05$ and ${ }^{* *} \mathrm{p}<0.05$ compared with the LPS group. For the bar charts: I, control; II, LPS only; III, Nar at 1,000 ng/ml; IV, Nar at $600 \mathrm{ng} / \mathrm{ml}$; and V, Nar at $200 \mathrm{ng} / \mathrm{ml}$.

cross the blood brain barrier to protect brain cells (20). All these data make the research of Nar feasible.

Oxidative stress is closely associated with neurodegenerative diseases (37). ROS play an essential role in oxidative stress. In the present study, LPS markedly increased the release of intracellular ROS from PC12 cells; however, pre-treatment with various concentrations of Nar decreased the intracellular ROS levels. It should be noted that CYP2E1 is also associated with LPS-induced oxidative stress and ROS production (38). Our results from western blot analysis demonstrated this view, which also revealed that the protective effects of Nar against
LPS-induced PC12 cell apoptosis may be associated with its specific inhibition of CYP2E1.

In addition, the enhanced tolerance capacity against oxidative stress gained our attention (Fig. 5). The protein levels of Nrf2, HO-1, SOD2 and GSS increased following exposure to LPS. Of note, the levels of these proteins were not altered when Nar treatment was used alone. Therefore, we speculate that Nar can not only enhance the antioxidant capacity through the downregulation of CYP2E1 protein expression, but can also maintain the balance of intracellular antioxidant protein expression. 


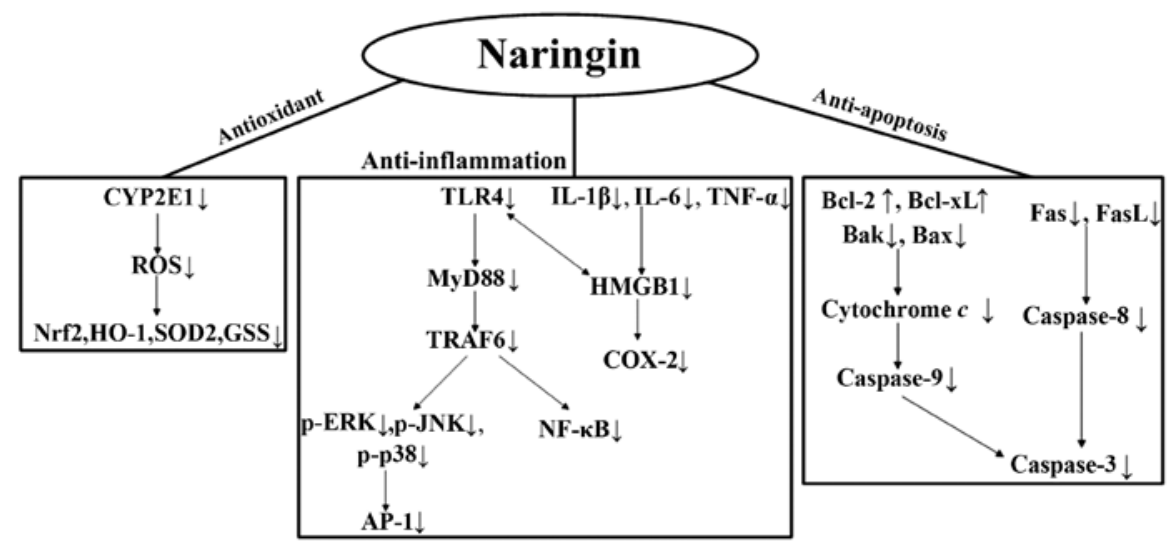

Figure 9. The conceivable mechanisms responsible for the protective effects of naringin (Nar) against lipopolysaccharide (LPS)-induced PC12 cell apoptosis.

LPS is a major activator of inflammation and a ligand for TLR4 (39). Upon LPS stimulation, inflammation is generated by TLR4 through the activation of downstream proteins, such as MyD88, TRAF6, NF- $\mathrm{BB}$, MAPKs and AP-1, resulting in the production of a wide range of pro-inflammatory cytokines and chemokines $(40,41)$. Moreover, NF- $\mathrm{kB}$ is an inducible transcription factor, which can be sensitized by TNF- $\alpha$, IL-1 $\beta$, LPS and ROS (42-44). The present study demonstrated that LPS has the ability to cause the robust transcriptional activity of NF- $\mathrm{KB}$ and to markedly increase the expression of pro-inflammatory cytokines, leading to $\mathrm{PC} 12$ cell apoptosis. However, all of changes were reversed by pre-treatment with Nar. In addition, our results of western blot analysis demonstrated that the phosphorylation of ERK, p38, JNK was inhibited in the presence of Nar. Thus, it is possible that Nar mediates the TLR4-related inflammatory pathway, and thereby alleviate inflammation in PC12 cells.

Apoptosis is accompanied by increased mRNA levels of pro-inflammatory cytokines, such as IL-1 $\beta$, IL-6, TNF- $\alpha$ (45). COX-2 is one of inflammatory early-response proteins (46), and its overexpression is associated with the stimulation of HMGB1. HMGB1 is a member of the damage-associated molecular pattern (DAMP) family of proteins that is secreted by necrotic brain cells (47). HMGB1 can bind to its receptor (TLR4) for mediating the inflammatory reaction (48); however, the potential mechanisms of action of the HMGB1-TLR4 pathway remain unclear. Nevertheless, in this study, Nar downregulated the levels of HMGB1 and TLR4-related proteins, and these results indicated that Nar effectively mitigated the secretion of inflammatory cytokines.

Finally, the death of PC12 cells induced by LPS is considered the common effect of oxidative stress, and inflammatory and apoptosis reactions. Bcl-2 is a critical unit for pro-survival function by maintaining the mitochondrial membrane. p53 is a critical suppressor molecule for Bcl-2. Upon oxidative or inflammatory stimulation, p53 is activated and associates with Bcl-2 by direct binding. The association of p53 with Bcl-2 can promote $\mathrm{Bcl}-2$ dissociation from the mitochondria and accelerate the permeabilization of the mitochondrial membrane. This causes Cyto $c$ release from the mitochondria to the cytoplasm and activates downstream of caspase apoptotic cascades $(49,50)$. Caspase- 3 is considered to be a unique factor of apoptosis in this cascade reaction. On the one hand, Fas/FasL and caspase- 8 are the upstream regulators of caspase-3 (51), and LPS can upregulate caspase-3 through Fas/FasL-caspase-3 pathway; on the other hand, upon LPS stimulation, LPS can downregulate $\mathrm{Bcl}-2, \mathrm{Bcl}-\mathrm{xL}$, and upregulate Bax, Bak, cytoplasmic Cyto $c$ and capase-9 (52). Finally, the caspase-3-related pathway is activated which eventually leads to apoptosis. The present study demonstrated that Nar markedly downregulate the protein expression levels of $\mathrm{p} 53$, Bak, cytoplasmic Cyto $c$, caspase-9, caspase- 8 and caspase- 3 , and the mRNA expression levels of Fas, FasL and Bax; Nar increased the expression of Bcl-2 and Bcl-xL. Our results demonstrated that the Nar suppressed LPS-induced PC12 cell apoptosis by mediating the expression of a series of caspase-3-related proteins.

In conclusion, our results demonstrate for the first time, at least to the best of our knowledge, that Nar reverses the oxidative stress, inflammation and the apoptosis of PC12 cells resulting from exposure to LPS. In Fig. 9, we summarize the underlying mechanisms responsible for the protective effects of Nar. As neuroinflammation is involved in the development of neurodegenerative diseases, Nar seems to act as a possible neuroprotective substance. Further studies are warranted to fully determine the protective effects of Nar and to elucidate all the underlying molecular mechanisms.

\section{Acknowledgements}

We would like to thank all colleagues within the Department of Pharmaceutical Analysis and correlative laboratory technicians from the Science Research Center of Dalian Medical University for their kind help and support.

\section{References}

1. Zhou WW, Lu S, Su YJ, Xue D, Yu XL, Wang SW, Zhang H, Xu PX, Xie XX and Liu RT: Decreasing oxidative stress and neuroinflammation with a multifunctional peptide rescues memory deficits in mice with Alzheimer disease. Free Radic Biol Med 74: 50-63, 2014.

2. Frankola KA, Greig NH, Luo W and Tweedie D: Targeting TNF- $\alpha$ to elucidate and ameliorate neuroinflammation in neurodegenerative diseases. CNS Neurol Disord Drug Targets 10: 391-403, 2011.

3. Khalil WK, Assaf N, ElShebiney SA and Salem NA: Neuroprotective effects of bee venom acupuncture therapy against rotenone-induced oxidative stress and apoptosis. Neurochem Int 80: 79-86, 2015. 
4. Ansari N, Khodagholi F, Amini M and Shaerzadeh F: Attenuation of LPS-induced apoptosis in NGF-differentiated PC12 cells via $\mathrm{NF}-\kappa \mathrm{B}$ pathway and regulation of cellular redox status by an oxazine derivative. Biochimie 93: 899-908, 2011.

5. He AY, Qiu LJ, Gao Y, Zhu Y, Xu ZW, Xu JM and Zhang ZH: The role of oxidative stress in neuromelanin synthesis in PC12 cells. Neuroscience 189: 43-50, 2011.

6. Shaerzadeh F, Ansari N, Amini M and Khodagholi F: Neuroprotective effects of oxazine derivative against LPS-induced oxidative stress via attenuation of NF- $\kappa \mathrm{B}$ pathway and regulation of cellular redox status in PC12 cells. Alzheimers Dement 7 : S616-S617, 2011

7. Lee JW, Lee YK, Yuk DY, Choi DY, Ban SB, Oh KW and Hong JT: Neuro-inflammation induced by lipopolysaccharide causes cognitive impairment through enhancement of beta-amyloid generation. J Neuroinflammation 5: 37, 2008.

8. Song X, Guo M, Wang T, Wang W, Cao Y and Zhang N: Geniposide inhibited lipopolysaccharide-induced apoptosis by modulating TLR4 and apoptosis-related factors in mouse mammary glands. Life Sci 119: 9-17, 2014.

9. Gadad BS, Britton GB and Rao KS: Targeting oligomers in neurodegenerative disorders: lessons from $\alpha$-synuclein, tau, and amyloid- $\beta$ peptide. J Alzheimers Dis 24 (Suppl 2): 223-232, 2011.

10. Nijveldt RJ, van Nood E, van Hoorn DE, Boelens PG, van Norren K and van Leeuwen PA: Flavonoids: a review of probable mechanisms of action and potential applications. Am J Clin Nutr 74: 418-425, 2001.

11. Maher P, Salgado KF, Zivin JA and Lapchak PA: A novel approach to screening for new neuroprotective compounds for the treatment of stroke. Brain Res 1173: 117-125, 2007.

12. Lv L, Zheng L, Dong D, Xu L, Yin L, Xu Y, Qi Y, Han X and Peng J: Dioscin, a natural steroid saponin, induces apoptosis and DNA damage through reactive oxygen species: a potential new drug for treatment of glioblastoma multiforme. Food Chem Toxicol 59: 657-669, 2013.

13. Zhang S and Peng J: Response to: 'hormetic effect of Rosa laevigata Michx in $\mathrm{CCl}_{4}$-induced hepatotoxicity and the presumptive role of PPARs'. Food Chem Toxicol 57: 389, 2013.

14. Wei Y, Xu Y, Han X, Qi Y, Xu L, Xu Y, Yin L, Sun H, Liu K and Peng J: Anti-cancer effects of dioscin on three kinds of human lung cancer cell lines through inducing DNA damage and activating mitochondrial signal pathway. Food Chem Toxicol 59: 118-128, 2013

15. Yu J, Dandekar DV, Toledo RT, Singh RK and Patil BS Supercritical fluid extraction of limonoids and naringin from grapefruit (Citrus paradisi Macf.) seeds. Food Chem 105 1026-1031, 2007.

16. Choi MS, Do KM, Park YS, Jeon SM, Jeong TS, Lee YK, Lee MK and Bok SH: Effect of naringin supplementation on cholesterol metabolism and antioxidant status in rats fed high cholesterol with different levels of vitamin E. Ann Nutr Metab 45: 193-201, 2001.

17. Raza SS, Khan MM, Ahmad A, Ashafaq M, Islam F, Wagner AP, Safhi MM and Islam F: Neuroprotective effect of naringenin is mediated through suppression of NF- $\mathrm{NB}$ signaling pathway in experimental stroke. Neuroscience 230: 157-171, 2013.

18. Sachdeva AK, Kuhad A and Chopra K: Naringin ameliorates memory deficits in experimental paradigm of Alzheimer's disease by attenuating mitochondrial dysfunction. Pharmacol Biochem Behav 127: 101-110, 2014

19. Ding G, Zhang Z, Chopp M, Li L, Zhang L, Li Q, Wei M and Jiang Q: MRI evaluation of BBB disruption after adjuvant AcSDKP treatment of stroke with IPA in rat. Neuroscience 271: $1-8,2014$.

20. Zbarsky V, Datla KP, Parkar S, Rai DK, Aruoma OI and Dexter DT: Neuroprotective properties of the natural phenolic antioxidants curcumin and naringenin but not quercetin and fisetin in a 6-OHDA model of Parkinson's disease. Free Radic Res 39: 1119-1125, 2005.

21. Rogers SW, Mandelzys A, Deneris ES, Cooper E and Heinemann S: The expression of nicotinic acetylcholine receptors by PC12 cells treated with NGF. J Neurosci 12: 4611-4623, 1992.

22. Zhao X, Cong X, Zheng L, Xu L, Yin L and Peng J: Dioscin, a natural steroid saponin, shows remarkable protective effect against acetaminophen-induced liver damage in vitro and in vivo. Toxicol Lett 214: 69-80, 2012.

23. Jia Y, Ji L, Zhang S, Xu L, Yin L, Li L, Zhao Y and Peng J: Total flavonoids from Rosa Laevigata Michx fruit attenuates hydrogen peroxide induced injury in human umbilical vein endothelial cells. Food Chem Toxicol 50: 3133-3141, 2012.
24. Omata Y, Saito Y, Fujita K, Ogawa Y, Nishio K, Yoshida Y and Niki E: Induction of adaptive response and enhancement of PC12 cell tolerance by lipopolysaccharide primarily through the upregulation of glutathione S-transferase A3 via Nrf2 activation. Free Radic Biol Med 45: 1437-1445, 2008.

25. Balachandran C, Sangeetha B, Duraipandiyan V, Raj MK, Ignacimuthu S, Al-Dhabi NA, Balakrishna K, Parthasarathy K, Arulmozhi NM and Arasu MV: A flavonoid isolated from Streptomyces sp. (ERINLG-4) induces apoptosis in human lung cancer A549 cells through p53 and cytochrome $c$ release caspase dependant pathway. Chem Biol Interact 224: 24-35, 2014.

26. Blatt NB, Boitano AE, Lyssiotis CA, Opipari AW Jr and Glick GD: Bz-423 superoxide signals apoptosis via selective activation of JNK, Bak, and Bax. Free Radic Biol Med 45: 1232-1242, 2008.

27. Chen YT, Shi D, Yang D and Yan B: Antioxidant sulforaphane and sensitizer trinitrobenzene sulfonate induce carboxylesterase-1 through a novel element transactivated by nuclear factor-E2 related factor-2. Biochem Pharmacol 84: 864-871, 2012.

28. Valencia-Olvera AC, Morán J, Camacho-Carranza R, Prospéro-García O and Espinosa-Aguirre JJ: CYP2E1 induction leads to oxidative stress and cytotoxicity in glutathione-depleted cerebellar granule neurons. Toxicol In Vitro 28: 1206-1214, 2014.

29. Kumar A, Prakash A and Dogra S: Naringin alleviates cognitive impairment, mitochondrial dysfunction and oxidative stress induced by D-galactose in mice. Food Chem Toxicol 48: 626-632, 2010.

30. Golechha M, Chaudhry U, Bhatia J, Saluja D and Arya DS: Naringin protects against kainic acid-induced status epilepticus in rats: evidence for an antioxidant, anti-inflammatory and neuroprotective intervention. Biol Pharm Bull 34: 360-365, 2011.

31. Kandhare AD, Ghosh P and Bodhankar SL: Naringin, a flavanone glycoside, promotes angiogenesis and inhibits endothelial apoptosis through modulation of inflammatory and growth factor expression in diabetic foot ulcer in rats. Chem Biol Interact 219: 101-112, 2014

32. Dong D, Xu L, Yin L, Qi Y and Peng J: Naringin prevents carbon tetrachloride-induced acute liver injury in mice. J Funct Foods 12: 179-191, 2015.

33. Wang D, Gao K, Li X, Shen X, Zhang X, Ma C, Qin C and Zhang L: Long-term naringin consumption reverses a glucose uptake defect and improves cognitive deficits in a mouse model of Alzheimer's disease. Pharmacol Biochem Behav 102: 13-20, 2012.

34. Golechha M, Sarangal V, Bhatia J, Chaudhry U, Saluja D and Arya DS: Naringin ameliorates pentylenetetrazol-induced seizures and associated oxidative stress, inflammation, and cognitive impairment in rats: possible mechanisms of neuroprotection. Epilepsy Behav 41: 98-102, 2014.

35. Mani VM and Sadiq AMM: Naringin modulates the impairment of memory, anxiety, locomotor, and emotionality behaviors in rats exposed to deltamethrin; a possible mechanism association with oxidative stress, acetylcholinesterase and ATPase. Biomed Prev Nutr 4: 527-533, 2014

36. Li P, Wang S, Guan X, Cen X, Hu C, Peng W, Wang Y and Su W: Six months chronic toxicological evaluation of naringin in Sprague-Dawley rats. Food Chem Toxicol 66: 65-75, 2014

37. Liu S, Han Y, Zhang T and Yang Z: Protective effect of trifluoperazine on hydrogen peroxide-induced apoptosis in PC12 cells Brain Res Bull 84: 183-188, 2011.

38. Pérez MJ and Cederbaum AI: Antioxidant and pro-oxidant effects of a manganese porphyrin complex against CYP2E1-dependent toxicity. Free Radic Biol Med 33: 111-127, 2002.

39. Li X, Lian LH, Bai T, Wu YL, Wan Y, Xie WX, Jin X and Nan JX: Cryptotanshinone inhibits LPS-induced proinflammatory mediators via TLR4 and TAK1 signaling pathway. Int Immunopharmacol 11: 1871-1876, 2011.

40. Cui L, Feng L, Zhang ZH and Jia XB: The anti-inflammation effect of baicalin on experimental colitis through inhibiting TLR4/NF- $\kappa \mathrm{B}$ pathway activation. Int Immunopharmacol 23: 294-303, 2014.

41. Lu SM, Yu CJ, Liu YH, Dong HQ, Zhang X, Zhang SS, Hu LQ, Zhang F, Qian YN and Gui B: S100A8 contributes to postoperative cognitive dysfunction in mice undergoing tibial fracture surgery by activating the TLR4/MyD88 pathway. Brain Behav Immun 44: 221-234, 2015.

42. Nadeau S and Rivest S: Role of microglial-derived tumor necrosis factor in mediating CD14 transcription and nuclear factor kappa B activity in the brain during endotoxemia. J Neurosci 20: 3456-3468, 2000.

43. Castello L, Froio T, Maina M, Cavallini G, Biasi F, Leonarduzzi G, Donati A, Bergamini E, Poli G and Chiarpotto E: Alternate-day fasting protects the rat heart against age-induced inflammation and fibrosis by inhibiting oxidative damage and NF- $\kappa \mathrm{B}$ activation. Free Radic Biol Med 48: 47-54, 2010. 
44. Zheng Y, Guo Z, He W, Yang Y, Li Y, Zheng A, Li P, Zhang Y, Ma J, Wen M, et al: Ephedrine hydrochloride protects mice from LPS challenge by promoting IL-10 secretion and inhibiting proinflammatory cytokines. Int Immunopharmacol 13: 46-53, 2012.

45. Mukhopadhyay P, Rajesh M, Horváth B, Bátkai S, Park O, Tanchian G, Gao RY, Patel V, Wink DA, Liaudet L, et al: Cannabidiol protects against hepatic ischemia/reperfusion injury by attenuating inflammatory signaling and response, oxidative/nitrative stress, and cell death. Free Radic Biol Med 50: 1368-1381, 2011

46. Abdelazeem AH, Abdelatef SA, El-Saadi MT, Omar HA, Khan SI, McCurdy CR and El-Moghazy SM: Novel pyrazolopyrimidine derivatives targeting COXs and iNOS enzymes; design, synthesis and biological evaluation as potential anti-inflammatory agents. Eur J Pharm Sci 62: 197-211, 2014.

47. Zhang J, Takahashi HK, Liu K, Wake H, Liu R, Maruo T, Date I, Yoshino T, Ohtsuka A, Mori S and Nishibori M: Anti-high mobility group box-1 monoclonal antibody protects the bloodbrain barrier from ischemia-induced disruption in rats. Stroke 42: 1420-1428, 2011

48. Park JS, Gamboni-Robertson F, He Q, Svetkauskaite D, Kim JY, Strassheim D, Sohn JW, Yamada S, Maruyama I, Banerjee A, et al: High mobility group box 1 protein interacts with multiple toll-like receptors. Am J Physiol Cell Physiol 290: C917-C924, 2006.
49. Chipuk JE and Green DR: How do BCL-2 proteins induce mitochondrial outer membrane permeabilization? Trends Cell Biol 18: 157-164, 2008.

50. Zeng KW, Liao LX, Zhao MB, Song FJ, Yu Q, Jiang Y and Tu PF: Protosappanin B protects PC12 cells against oxygen-glucose deprivation-induced neuronal death by maintaining mitochondrial homeostasis via induction of ubiquitin-dependent p53 protein degradation. Eur J Pharmacol 751: 13-23, 2015.

51. Miller DK: The role of the Caspase family of cysteine proteases in apoptosis. Semin Immunol 9: 35-49, 1997.

52. Islam Z, Amuzie CJ, Harkema JR and Pestka JJ: Neurotoxicity and inflammation in the nasal airways of mice exposed to the macrocyclic trichothecene mycotoxin roridin a: kinetics and potentiation by bacterial lipopolysaccharide coexposure. Toxicol Sci 98: 526-541, 2007 